PERSPECTIVAS

\title{
Reflexões sobre o engajamento de estudantes ensaio no Ensino Remoto Emergencial
}

Tobias Espinosa

https://orcid.org/0000-0002-6958-8274

Artigo produzido a partir de parecer emitido ao artigo: Paula, H. F., Talim, S. L., Salema, C. S., \& Lamilo, V. R. (2021). Engajamento de estudantes em um Ensino Remoto e Emergencial de Física. Ensaio Pesquisa em Educação em Ciências, 23.

\section{RESUMO:}

Em estudo anterior sobre o engajamento dos estudantes de uma disciplina de Física em uma escola pública federal, reestruturada para o Ensino Remoto Emergencial (ERE) em função da pandemia da COVID-19, foram identificados indícios de engajamento discente nas dimensões cognitivocomportamental (e.g., participação e compromisso com estratégias de estudo) e emocional (e.g., reações positivas e de identificação com a escola e os temas estudados). A partir das reflexões geradas durante o processo de arbitragem do trabalho mencionado, neste artigo são expandidas duas discussões: diferentes perspectivas teóricas e indicadores do construto engajamento; e fatores que podem influenciar o engajamento dos estudantes no ERE.

\section{Reflexiones sobre el compromiso (engagement) de los estudiantes en la Enseñanza Remota de Emergencia}

\section{RESUMEN:}

En un estudio anterior sobre el compromiso de los estudiantes en una materia de Física en una escuela pública federal, reestructurada para la Enseñanza Remota de Emergencia (ERE) debido a la pandemia de COVID19, se identificaron evidencias de la participación de los estudiantes en las dimensiones cognitivo-conductual (p. ej., participación y compromiso con las estrategias de estudio) y emocional (p. ej., reacciones positivas y de

Palavras-chave: COVID-19; Ensino Remoto Emergencial; Engajamento. identificación con la escuela y los temas estudiados). A partir de las reflexiones que se generaron durante el proceso de arbitraje del trabajo mencionado, en este artículo se amplían dos discusiones: diferentes perspectivas teóricas e indicadores del constructo compromiso (engagement); y factores que pueden influir en la participación de los estudiantes en el ERE.

Palabras clave: COVID-19; Enseñanza Remota de Emergencia; Compromiso. 


\section{Reflections on Student Engagement in Emergency Remote Learning}

\section{ABSTRACT:}

In a previous study on the students engagement in a physics course in a federal public school, restructured for Emergency Remote Teaching (ERT) due to the COVID-19 pandemic, was pointed out evidences of student engagement in the cognitive-behavioral dimensions (e.g., participation and commitment to study strategies) and emotional (e.g., positive reactions and identification with the school and the themes studied). Based on the

Key words: COVID-19; Emergency Remote Learning; Engagement. reflections risen up during the referee process of the mentioned research, two discussions are expanded in this paper: different theoretical perspectives and indicators of the engagement construct; and factors that can influence student engagement in the ERT.

\section{INTRODUÇÃO}

Segundo dados da UNESCO (2020), mais de 98\% da população mundial de estudantes (cerca de 1,9 bilhão de crianças e jovens) foi afetada pelo fechamento das escolas devido à pandemia da COVID-19. Por consequência, a educação escolar sofreu profundas modificações. Em especial, criou-se uma dependência por recursos tecnológicos capazes de viabilizar o ensino nesse período. No Brasil, isso agravou problemas de qualidade da educação pública e desigualdade educacional (Cunha, Silva \& Silva, 2020; Freitas, Heidemann \& Araujo, 2021). De acordo com dados do CETIC $^{1}$ (2019), 29\% das residências brasileiras não possuem acesso à internet, seja por fatores econômicos ou relacionados à indisponibilidade de sinal na localidade. Dos entrevistados pela entidade, $41 \%$ afirmaram não possuir computador e $49 \%$ disseram que não sabiam utilizar a internet.

Nesse cenário, instituiu-se, na maioria das escolas públicas e privadas do Brasil, o Ensino Remoto Emergencial (ERE). O ERE é diferente do que é conhecido como ensino online (pré-pandemia), principalmente em termos de estrutura da disciplina, dos materiais e da avaliação (Affouneh, Salha \& Khlaif, 2020). No ensino online, também chamado de Educação a Distância, os materiais e a avaliação são estruturados para ambientes virtuais de aprendizagem específicos e os professores são auxiliados por tutores que mantém contato constante e direto com os estudantes; por outro lado, no ERE, o professor, sozinho e usualmente sem formação adequada para o ensino online, adapta seus materiais e avaliações do ensino presencial para o ambiente virtual, sem auxílio pedagógico. A diferença se acentua se considerarmos que, durante este período de pandemia, professores e estudantes estão vivendo em um estado constante de estresse, ansiedade e incerteza (Singh et al., 2020; Castro, Junqueira \& Cicuto, 2020, Vieira et al., 2020). Diante disso, a seguinte indagação passou a ser

1 CETIC é a sigla para Centro Regional de Estudos para o Desenvolvimento da Sociedade da Informação. Informações sobre a entidade podem ser acessadas em:

$\underline{\text { https://cetic.br }}$ 
recorrente: é possível, a despeito de todas condições adversas geradas pela pandemia da COVID-19, engajar os estudantes nas atividades propostas durante o ERE?

Tendo em vista esse contexto, a investigação de Paula et al. (2021) teve como propósito analisar informações de um questionário, elaborado por um grupo de professores de Física de uma escola pública federal, sobre o engajamento de 99 estudantes em uma disciplina de Física reestruturada para o ERE, em função da pandemia da COVID-19. Por meio de análise fatorial, os autores identificaram três dimensões de engajamento: cognitivo-comportamental, emocional e social. A análise dos resultados apontou para um engajamento dos alunos, principalmente nas dimensões cognitivo-comportamental e emocional.

Frente à escassez de trabalhos que avaliem o cenário educacional durante a pandemia, a pesquisa realizada é relevante e tem potencial para contribuir para as discussões da área de pesquisa em Ensino de Física. Ademais, apesar do aumento no número de pesquisas sobre engajamento discente em nível internacional, o tema ainda é escasso no cenário brasileiro (Irala \& Oliveira, 2020; Rigo, 2020). Durante o processo de arbitragem, dois pontos suscitaram reflexões, um relacionado ao próprio construto engajamento e às formas de obter medidas precisas sobre ele, e outro acerca dos fatores que podem influenciar o engajamento discente no ERE.

Neste artigo, a partir da literatura, são expandidas as discussões sobre esses dois pontos. Espera-se, com isso, contribuir para o diálogo iniciado no trabalho de Paula et al. (2021) e para futuras pesquisas a respeito do engajamento de estudantes no ERE.

\section{PERSPECTIVAS TEÓRICAS E INSTRUMENTOS DE COLETA DE DADOS PARA AFERIÇÃO DO ENGAJAMENTO DISCENTE}

Parte significativa do trabalho de Paula et al. (2021) se debruça em apresentar um questionário, elaborado por professores, para medir diferentes dimensões do construto engajamento. Na versão original do artigo, submetida à avaliação, os autores se referiam aos resultados advindos do questionário como medidas diretas do engajamento discente. No processo de arbitragem, foram suscitados os seguintes questionamentos: em que medida o questionário mede, de forma direta, o engajamento dos estudantes? Seriam necessários outros instrumentos? A partir disso, na versão final do artigo, os autores passaram a se referir aos resultados do questionário como evidências de engajamento. Ainda assim, a reflexão sobre as formas de mensurar o engajamento dos estudantes, bem como dos diferentes indicadores que poderiam resultar em uma análise mais acurada é pertinente.

Nesse sentido, primeiramente, são discutidas algumas perspectivas sobre o engajamento discente e, em seguida, ponderações sobre instrumentos de medida do construto e possíveis indicadores de engajamento que podem se constituir como base para análises desse tipo.

É consenso na literatura o caráter multidimensional do construto engajamento (Fredricks et al., 2016). No entanto, não há uma definição unívoca acerca de quais são essas dimensões. A proposta defendida e utilizada por Paula e colaboradores é a de Fredricks, Blumenfeld e Paris $(2004,2016)$, que concebem o engajamento em quatro dimensões: comportamental, cognitiva, emocional e social. O engajamento comportamental está relacionado à participação dos estudantes nas atividades pedagógicas. A dimensão cognitiva diz respeito ao compromisso e vontade expressos pelos estudantes em estratégias utilizadas por eles para aprender. O engajamento emocional está relacionado com as reações (positivas e negativas), o senso de pertencimento e de identificação com a escola e/ou conteúdo de estudo. 
Por fim, a dimensão social do engajamento é expressa nas interações sociais realizadas pelos discentes.

Reeve e Tseng (2011) propõem uma outra dimensão do engajamento estudantil, a agêntica, não explorada no trabalho de Paula e colaboradores. O engajamento agêntico está relacionado com processos nos quais os estudantes agem de forma intencional e proativa no sentido de enriquecer o que e como devem aprender um determinado conteúdo. Isso pode ser manifestado em uma aula quando o estudante, por exemplo, expressa suas preferências, oferece sugestões e contribuições, levanta questionamentos e solicita recursos para melhorar sua aprendizagem.

Outra perspectiva sobre o tema é a do engajamento disciplinar produtivo, desenvolvida por Engle e Conant (2002), que permite avaliar o progresso no engajamento dos estudantes em situações de ensino a partir de três dimensões principais: engajamento, engajamento disciplinar e engajamento disciplinar produtivo. Diferentemente das abordagens de Fredricks, Blumenfeld e Paris (2004) e Reeve e Tseng (2011), o engajamento disciplinar produtivo de Engle e Conant (2002) permite uma apreciação dinâmica do engajamento estudantil, utilizando a análise discursiva como principal indicador do construto.

$\mathrm{Na}$ perspectiva de Engle e Conant (2002), o engajamento pode ser constatado nas interações discursivas dos estudantes entre si, e com o docente em sala de aula (presencial ou virtual). A análise do engajamento pode ser guiada pelas seguintes questões (Engle \& Conant, 2002, p. 402): "como os alunos estão participando? Que proporção de estudantes está participando? E como as contribuições dos alunos respondem às de outros colegas?". Essa avaliação, no contexto do ERE, pode ser realizada a partir da análise das interações discursivas em encontros síncronos, fóruns e aplicativos de mensagem.

No engajamento disciplinar constata-se interações em situação de ensino; há uma ligação entre o que os estudantes fazem e os discursos considerados disciplinares e escolares. O cumprimento de normas e procedimentos específicos da escola e da disciplina indicam que o estudante está engajado disciplinarmente (e.g., formatação de trabalhos de acordo com modelos estabelecidos pelo docente ou pela escola, entrega das tarefas nas datas acordadas etc.).

Já no engajamento disciplinar produtivo o estudante expressa o entendimento acerca dos conceitos e práticas em estudo. Ele pode ser constatado, por exemplo, na progressiva sofisticação de argumentos científicos utilizados pelos discentes (Engle \& Conant, 2002).

O engajamento do estudante também pode ser entendido como uma manifestação de sua motivação para aprender. Em outras palavras, fomentar diferentes tipos de motivação pode ser uma fonte de engajamento discente em atividades didáticas (Reeve, 2013). Nesse sentido, a Teoria da Autodeterminação, de Deci e Ryan (1985), apresenta um dos principais modelos utilizados na literatura para explicar a motivação a partir de necessidades humanas básicas relacionadas ao contexto social. Essa teoria pode ser particularmente útil para a compreensão do engajamento.

O modelo de Deci e Ryan (1985) parte do pressuposto ontológico de que todos os indivíduos possuem três necessidades psicológicas básicas que, quando satisfeitas, os motivam a agir, são elas: autonomia (percepção de possibilidade de escolha), competência (percepção de eficácia e de que possui as habilidades necessárias para atingir seus objetivos) e pertencimento/envolvimento (percepção de conexão com o grupo e de que é valorizado por ele). Se no estudo, seja remoto ou presencial, o aluno tem oportunidades de suprir essas necessidades, tenderá a se engajar. Na seção seguinte são discutidos fatores relacionados à prática docente no ensino online que podem favorecer a motivação e, consequentemente, $\mathrm{o}$ 
engajamento. Cabe salientar que a motivação é condição necessária, mas não suficiente para o engajamento (Appleton, Christenson \& Furlong, 2008).

Seja qual for a perspectiva adotada para o estudo do engajamento discente, pesquisadores da área apontam que há muitos problemas em relação à medida do construto (Fredricks \& McColskey, 2012; Veiga et al., 2014; Fredricks et al., 2016). Em uma revisão da literatura sobre o tema, realizada por Fredricks e McColskey (2012), foi identificado: limitada quantidade de questionários que abrangem as diferentes dimensões do engajamento; utilização indiscriminada das diferentes dimensões; pouca evidência para suporte à validade dos instrumentos; uso do construto de forma generalista, independente do contexto, domínio de ações e disciplina. Com relação a este último, os autores ainda afirmam que é escassa a quantidade de questionários sobre engajamento de estudantes em aulas de ciências e matemáticas. Nesse sentido, o trabalho de Paula et al. (2021) auxilia a reduzir essa lacuna.

Fredricks e McColskey (2012) ressaltam que os métodos de coleta de dados sobre engajamento dos estudantes influenciam no nível de aprofundamento em um tipo de engajamento em detrimento dos demais. Por exemplo, entrevistas e relatos individuais dos alunos possibilitam um aprofundamento nas dimensões cognitiva e emocional do engajamento; enquanto a dimensão comportamental pode ser melhor explicitada na observação direta dos estudantes em ambiente de ensino.

Em levantamento na literatura, Fredricks e McColskey (2012) destacaram cinco técnicas que são utilizadas para a aferição de engajamento dos estudantes, são elas: questionário autodeclaratório, amostra por experiência, avaliação do professor, entrevista e observação. Cada um desses instrumentos possui potencialidades e limitações.

O questionário autodeclaratório, além do tipo de instrumento mais utilizado em pesquisas sobre engajamento discente, é o mais prático e possibilita a comparação de resultados entre turmas e escolas. No entanto, como aponta Fredricks e McColskey (2012), os estudantes nem sempre são honestos em suas respostas com esse tipo de instrumento, principalmente quando são aplicados pelo professor. Outra limitação é que a aplicação do questionário considerando uma análise retrospectiva dos estudantes precisa contar com a lembrança que os indivíduos têm dos eventos, que pode, em grande medida, ser afetada por vieses cognitivos (Hill \& Betz, 2005).

O problema da avaliação retrospectiva pode ser atenuado com a técnica da amostra por experiência. Nela, os estudantes carregam algum dispositivo eletrônico que dispara um alarme em situações e momentos estratégicos, nos quais lhes é solicitado que respondam algumas poucas questões que avaliam o quão engajados estão no momento. As limitações desse tipo de pesquisa são: altos investimentos de tempo e disposição dos participantes. Além disso, os questionários usualmente utilizados não contam com um número elevado de questões e, consequentemente, não são capazes de cobrir a multidimensionalidade do construto (Fredricks \& McColskey, 2012).

A avaliação do engajamento realizada pelo professor pode ser particularmente útil quando os estudantes têm limitações para responder questionários. Também pode ser utilizado para avaliar a dimensão comportamental do engajamento, uma vez que é difícil de captá-la em questionários autodeclaratórios (Fredricks \& McColskey, 2012).

Por fim, entrevistas e observações também podem ser utilizadas na coleta de dados a respeito do engajamento discente. A primeira possibilita a identificação das razões de variações nos níveis de engajamento; ou pode fornecer detalhes sobre como os alunos dão sentido às experiências que vivenciam. Apesar disso, as entrevistas possuem limitações similares aos questionários autodeclaratórios retrospectivos. Já a observação possibilita uma 
análise detalhada do engajamento, principalmente comportamental, favorecendo análises que considerem fatores contingentes e contextuais. As observações podem requerer muito tempo do pesquisador e podem não prover dados tão confiáveis, caso não sejam utilizadas com outra fonte de evidência (Fredricks \& McColskey, 2012). É evidente a importância da utilização de múltiplas fontes de evidência para uma análise mais acurada e multidimensional do engajamento discente (Veiga et al., 2014).

As escolhas teórica e metodológica de Paula e colaboradores foram: as quatro dimensões do engajamento de Fredricks et al. (2016) (comportamental, cognitiva, emocional e social) e a coleta de dados por meio de questionário autodeclaratório, respectivamente. Nesta seção, a discussão foi expandida a partir da apresentação de outras perspectivas para pesquisa sobre engajamento discente e de uma análise crítica acerca da medida do construto. Tais contribuições podem ser úteis para o delineamento e condução de pesquisas acerca do engajamento de estudantes em atividades remotas no período de pandemia da COVID-19.

\section{FATORES QUE PODEM INFLUENCIAR O ENGAJAMENTO DOS ESTUDANTES NO ERE}

Altos níveis de engajamento podem levar os estudantes a melhores desempenhos nas atividades acadêmicas, aumento na persistência, maior participação em atividades extracurriculares e maior interação social (Baños, Noah \& Harada, 2019; Bergdahl et al., 2020; Bond, 2020). Além disso, reduzem as taxas de evasão escolar (Fraysier, Reschly \& Appleton, 2020). Esses resultados indicam a importância de construirmos entendimento sobre quais fatores (didáticos) são capazes de fomentar o engajamento dos estudantes, sobretudo durante o ERE.

No artigo arbitrado, Paula e colaboradores destacaram que encontraram evidências de engajamento dos estudantes mesmo em um curso com limitações, como o baixo número de alunos que podiam participar dos encontros síncronos semanais.

Em parecer foi solicitado aos autores que descrevessem em maiores detalhes a metodologia de ensino empregada no período analisado, pois, assim, seria possível entender, mesmo que parcialmente, quais os fatores que influenciaram no engajamento discente no contexto do ERE. Apesar de não ser o foco do artigo analisado, é um tema que merece reflexão, pois tem implicações práticas e imediatas para o ensino. Nesta seção, são apresentados alguns fatores que podem fomentar o engajamento dos estudantes no contexto do ERE, segundo trabalhos da literatura.

Fatores externos ao contexto da turma, como a própria escola, a família, a comunidade e a cultura influenciam no engajamento (Fredricks, Blumenfeld \& Paris, 2004). Contudo, o foco do presente artigo, em diálogo com o trabalho de Paula et al. (2021), está em suscitar reflexões sobre as influências no engajamento dos estudantes ligadas ao nível da sala de aula (turma, relações com o professor, colegas e com o material didático), mesmo que virtual, e das necessidades psicológicas individuais.

De acordo com Khlaif, Salha e Kouraichi (2021), três fatores principais, identificados a partir de uma breve revisão da literatura, influenciam no engajamento dos estudantes no ensino online, são eles: suporte social, a qualidade do conteúdo disponibilizado e das atividades e a autoeficácia dos estudantes com relação ao uso do computador. 
O suporte social pode ser contemplado pelo professor, pelos familiares e pelos colegas. A interação dos estudantes com seus pares e com o professor é crucial para o estabelecimento de um ambiente de suporte social (Marks, 2000; Czerkawski \& Lyman, 2016; Nortvig, Petersen \& Balle, 2018; Liu \& Zhang, 2020).

O suporte do professor, que pode ser acadêmico ou interpessoal, influencia nas dimensões cognitiva, emocional e comportamental do engajamento dos estudantes (Fredricks, Blumenfeld \& Paris). No entanto, o suporte acadêmico em um ambiente social negativo pode levar os estudantes a se desengajarem emocionalmente. Assim como o foco exclusivo no suporte social, deixando o acadêmico em segundo plano, pode acarretar baixos níveis de engajamento cognitivo dos discentes (Fredricks, Blumenfeld \& Paris, 2004). A combinação do suporte acadêmico e social é fundamental para estimular o engajamento dos alunos.

O engajamento cognitivo pode ser fomentado quando os estudantes são colocados em grupos para debaterem diferentes pontos de vista, recebendo suporte de seus colegas (Fredricks, Blumenfeld \& Paris, 2004). Quando estrategicamente estruturados, os grupos de alunos podem contar com indivíduos comprometidos individualmente com o bem do grupo e altos níveis de confiança entre os membros, envolvendo sentimentos de carinho e benevolência (Preast, 2012; Espinosa, Araujo \& Veit, 2016). Ainda é destacado na literatura que, em atividades em grupo, os estudantes são capazes de resolver problemas mais complexos e que as soluções desenvolvidas são significativamente superiores do que aquela desenvolvida sozinha pelo melhor indivíduo do grupo (Heller \& Hollabaugh, 1992). Esses resultados podem ser alcançados por meio da construção de grupos heterogêneos ${ }^{2}$ em relação aos conhecimentos, às experiências pessoais e aos interesses; da valorização do trabalho em grupo em termos avaliativos; e da proposição de tarefas desafiadoras, que sejam significativas para o grupo (Espinosa, Araujo \& Veit, 2016). Nesse sentido, é razoável considerar que métodos interativos de ensino, como a Aprendizagem Baseada em Equipes ${ }^{3}$ (Michaelsen, Knight \& Fink, 2004; Espinosa, Araujo \& Veit, 2016), podem estimular não apenas a dimensão cognitiva do engajamento, mas também as dimensões emocional, comportamental e social.

A qualidade do conteúdo e materiais disponibilizados, que também influencia no engajamento no ensino online, envolve atividades bem organizadas, com exposição clara dos objetivos de aprendizagem e de fácil utilização no contexto digital (Chen, Bastedo \& Howard, 2018; Keržič et al., 2019). Além disso, a variedade de recursos pode influenciar positivamente no engajamento discente (Lee \& Hannafin, 2016). Bovermann e Bastiaens (2020) defendem que atividades gamificadas podem ser úteis para engajar os alunos no ensino online.

A proposta de problemas autênticos, isto é, direcionados ao mundo real e que tenham significado para os estudantes, é outro fator que potencializa o engajamento deles nas atividades escolares. Esse fator é particularmente importante para o ensino de Ciências e pode ser fomentado a partir da implementação de metodologias ativas como a Aprendizagem Baseada em Projetos (Blumenfeld et al., 1991; Pasqualetto, 2018).

A autoeficácia dos estudantes com relação ao uso do computador - que significa suas crenças sobre sua capacidade de realizar um conjunto de ações relacionadas ao uso do

\footnotetext{
2 Em Espinosa, Araujo e Veit (2016) é possível encontrar um modelo de questionário destinado à construção de grupos heterogêneos de aprendizagem.

3 Palsolé e Awalt (2008) utilizaram a Aprendizagem Baseada em Equipes, com algumas alterações, em um curso totalmente online e assíncrono e obtiveram sucesso em termos de desempenho, persistência e atitudes dos estudantes em relação ao método. Os autores ainda destacam que os grupos de aprendizagem foram determinantes para que os estudantes se mantivessem ativos durante o curso.
} 
computador -, influencia no engajamento dos discentes no ensino online. Como argumenta Bandura (1997), psicólogo criador do conceito de autoeficácia, não se trata de ter ou não certas habilidades, mas sim do julgamento feito pelo indivíduo sobre sua capacidade. Assim, indivíduos que não acreditam que são capazes de lidar com as demandas acadêmicas por meio do uso do computador, mesmo que tenham as habilidades para isso, tendem a se engajarem menos nas atividades. Cabe salientar que autoeficácia é um construto psicológico que precisa ser delimitado em termos de um contexto e um conjunto de ações específicas. Isto é, o estudante que se sente capaz de navegar pelas redes sociais, por exemplo, não necessariamente julgará a si próprio como capaz de realizar uma pesquisa acadêmica no mesmo instrumento, ou realizar as atividades em um ambiente virtual de aprendizagem específico.

Ademais, o engajamento depende da autoeficácia dos alunos com relação às demandas necessárias da disciplina. Por exemplo, na Física o aluno que se sente capaz de resolver problemas e compreender conceitos tem mais chances de se engajar nas atividades didáticas, sejam presenciais ou online.

O desenvolvimento de crenças de autoeficácia positivas com relação à aprendizagem do conteúdo específico e em relação a ações de manuseio das ferramentas digitais necessárias para cumprir as demandas acadêmicas se mostra um fator importante a ser considerado para estimular o engajamento discente. De acordo com Bandura (1997), existem quatro fontes principais de autoeficácia: experiências de domínio, experiências vicárias, persuasão social e fatores fisiológicos e emocionais.

Experiências de domínio são episódios de sucesso ou fracasso vividos pelo estudante por meio de sua participação ativa em alguma ação. Experiências passadas positivas com relação à utilização do computador tendem a aumentar os níveis de autoeficácia do aluno nesse domínio. No caso de alunos com pouca experiência na utilização de recursos digitais, a incorporação gradual de ferramentas, tutoriais explicativos e suporte de professores, tutores ou colegas pode auxiliá-los a angariar experiências positivas.

As experiências vicárias são observações de outras pessoas (e.g., colegas de aula) realizando atividades específicas. Observar os colegas interagindo de forma satisfatória com o computador, ou resolvendo problemas de física, por exemplo, pode fazer com que o estudante se sinta capaz de fazer o mesmo. Nesse sentido, a utilização de tarefas que estimulem o trabalho em grupo pode ser particularmente útil para aumentar os níveis de autoeficácia discente.

A persuasão social inclui o julgamento verbal e não verbal de outras pessoas (colegas ou professores). O incentivo sincero dado por um professor, mostrando ao aluno que ele é capaz de realizar as atividades demandadas, pode auxiliá-lo a construir crenças de autoeficácia positivas. $\mathrm{O}$ feedback constante do docente às tarefas realizadas pelos alunos pode persuadi-lo acerca de suas próprias capacidades de realizar as atividades propostas.

Por fim, o estado fisiológico e emocional de um indivíduo (seu humor, estresse, ansiedade etc.), que surge ao realizar uma tarefa, serve como referência para o julgamento sobre sua capacidade de realizá-la. No ambiente escolar, uma avaliação toda calcada em provas pode acarretar níveis de estresse que afetam negativamente o julgamento do estudante acerca de suas capacidades. Por isso, recomenda-se uma avaliação formativa, ao longo de todo o processo didático, e diversificada (Espinosa, Araujo \& Veit, 2019).

Por meio da lente teórica da Teoria da Autodeterminação, também é possível identificar alguns fatores que possibilitam o engajamento discente no ERE. De acordo com Deci e Ryan (1985), o progresso de uma situação amotivada para a motivação extrínseca e para a 
motivação intrínseca ocorre a partir do suporte às três necessidades psicológicas básicas (autonomia, competência e pertencimento/envolvimento), descritas na seção anterior. No contexto pedagógico, a prática docente pode influenciar a motivação discente a partir do suporte à autonomia, de estrutura (competência) e de envolvimento (Deci \& Ryan, 2008; Lietaert et al., 2015; Vollet, Kindermann \& Skinner, 2017).

No contexto de ensino online, o suporte à autonomia provido pelo professor envolve considerar a perspectiva dos estudantes (conhecimentos prévios, dificuldades estruturais, relacionadas ao contexto, e de aprendizagem), permitir escolhas acerca dos objetivos e meios de aprendizagem, evitar linguagem controladora e tentar reduzir a demanda e estresse dos alunos (Chiu, 2021). Chiu (2021), amparado pelos trabalhos de Vansteenkiste et al. (2005), Skinner et al. (2008), Reeve (2013) e Bedenlier et al. (2020), argumenta que, com suporte à autonomia, os estudantes têm melhor concentração (engajamento comportamental), gostam mais de realizar as atividades (engajamento emocional), interagem com o professor durante o processo de aprendizagem (engajamento agêntico) e têm mais chance de se engajarem cognitivamente, pois participam das escolhas com relação aos objetivos e meios de aprendizagem.

Métodos ativos de ensino, baseados no modelo de Sala de Aula Invertida (Bergmann \& Sams, 2012; Espinosa, Araujo \& Veit, 2016), como o Ensino sob Medida (Novak et al., 1999; Araujo \& Mazur, 2013), indicam estratégias para o professor considerar a perspectiva dos alunos na condução de suas aulas. $\mathrm{O}$ docente pode pedir aos alunos que, em momento assíncrono, leiam um texto ou assistam a um vídeo, e respondam a um breve questionário com questões sobre o conteúdo estudado e uma questão de feedback, em que é solicitado que os alunos indiquem as dúvidas e dificuldades que tiveram ao estudar o material. Em momento síncrono (ou assíncrono, caso o contexto exija), o professor pode realizar pequenas exposições respondendo às dúvidas dos alunos na tarefa assíncrona. Assim, pode-se, ao prover suporte à autonomia, estimular a motivação e, consequentemente, o engajamento dos estudantes.

A estrutura (que auxilia os estudantes a se sentirem competentes) envolve o desenvolvimento de atividades online bem estruturadas (de qualidade para os objetivos desejados e com guias bem delineados) e que possibilitem a interação entre estudantes e entre estes e o professor. Além disso, é importante que o professor providencie feedback constante aos alunos (Chiu, 2021). Como destacado anteriormente, a qualidade das atividades influencia no engajamento discente, principalmente nas dimensões cognitivo e comportamental.

Por fim, o suporte ao envolvimento do estudante pode ser oferecido pelo professor por meio de comportamentos de cordialidade, demonstração de afeto e atenção às necessidades individuais (Skinner et al., 2008; Vollet, Kindermann \& Skinner, 2015). Esse tipo de comportamento pode ser caracterizado pelo que na literatura é conhecido por atenção pedagógica (pedagogical caring) (Wentzel, 1997).

Métodos ativos de ensino cujas propostas são desenvolvidas a partir das dificuldades dos alunos (como o Ensino sob Medida, destacado anteriormente) podem contribuir para a percepção do aluno de que está sendo valorizado (Moraes, Heidemann \& Espinosa, 2020). Os métodos ativos também contribuem para o envolvimento dos estudantes na medida em que estruturam atividades que envolvem o trabalho colaborativo.

O suporte ao envolvimento dos alunos perpassa a interação entre colegas e entre alunos e professor. Sasseron (2019) enfatiza, principalmente a partir de trabalhos da literatura nacional (Faria, 2008; Julio, Vaz \& Fagundes, 2011), o papel de destaque das interações entre os alunos, e entre eles e o professor, em sala de aula para o surgimento e manutenção do engajamento. Assim, os encontros síncronos, por meio de vídeo ou chat, mostram-se importantes para motivar os estudantes e engajá-los nas atividades didáticas (Chiu, 2021). No 
âmbito do ensino remoto emergencial brasileiro, essa interação é comprometida, uma vez que em diversos contextos, como no discutido no artigo analisado (Paula et al., 2021), os encontros síncronos não são utilizados de forma recorrente, devido à falta de acesso de grande parte dos estudantes a recursos tecnológicos.

Chiu (2021) destaca que boas relações entre estudantes e professor podem encorajá-los a participar das atividades (engajamento comportamental), melhorar suas atitudes com relação à disciplina e às atividades (engajamento emocional), dar-lhes confiança para completarem tarefas desafiadoras (engajamento cognitivo) e encorajá-los a explicitarem suas dúvidas e dificuldades (engajamento agêntico). Cabe salientar que um comportamento atencioso ao aluno pode agir de forma a persuadi-lo de que é capaz de realizar as atividades solicitadas, aumentando seus níveis de autoeficácia com relação às demandas acadêmicas.

Em síntese, pode-se constatar que tanto pelo viés direto do engajamento, ou mediado pela motivação, três fatores influenciam fortemente o engajamento discente em atividades online, são eles: atividades bem orientadas com certo grau de flexibilidade, de qualidade e específicas para o contexto de ERE; suporte social, emocional e acadêmico aos estudantes; e a incorporação de métodos ativos de ensino.

Mais do que identificar se há ou não engajamento discente nas atividades do ERE, como realizado por Paula et al. (2021), é importante mapear as causas, ou, pelo menos, providenciar ao leitor descrições do contexto, do(s) método(s) de ensino adotado e das atividades que sejam suficientes para a formulação de hipóteses que os relacionem com os níveis (e dimensões) de engajamento identificados. Desse modo, o professor interessado em engajar seus estudantes nesse período de dificuldades pode ter algumas alternativas para incorporar em sua prática.

\section{CONSIDERAÇÕES FINAIS}

Neste artigo, foi realizada uma breve discussão sobre algumas perspectivas e dimensões do engajamento discente, diferentes formas de medir o construto e os fatores que podem impactar no engajamento do aluno durante o Ensino Remoto Emergencial (ERE). A necessidade de tratar esses temas surgiu da análise do artigo de Paula et al. (2021), que apresenta uma investigação, realizada por meio de um questionário autodeclaratório, do engajamento de um grupo de estudantes em uma disciplina de Física de uma escola pública federal durante a pandemia da COVID-19.

Apesar das facilidades associadas ao uso de questionários de engajamento autodeclaratórios, sobretudo em contexto de pandemia, estudos de maior profundidade exigem outras fontes de coleta de dados. Além das vantagens óbvias da utilização de múltiplas fontes de evidência, que possibilitam a triangulação de dados, o caráter multidimensional do engajamento (perspectiva adotada por Paula e colaboradores) requer o uso de múltiplas técnicas de coleta de dados. Por exemplo, o questionário autodeclaratório é mais adequado para apreender o engajamento emocional e cognitivo, enquanto que a observação é capaz de aferir de forma mais precisa o engajamento comportamental.

Entender os fatores que levam os estudantes a se engajarem no ERE é tão importante quanto analisar o aumento ou redução nos níveis engajamento discente. Nesse sentido, destacam-se a utilização de métodos ativos de ensino, o suporte social e acadêmico provido pelo professor e a qualidade do material de estudo (adequado à realidade do estudante). Os dois primeiros fatores colocam em evidência a importância da interação entre alunos e entre estes e o professor. Aulas síncronas, mesmo que em pouca quantidade, podem ser cruciais 
para o fomento e manutenção do engajamento. Mesmo nos casos em que isso não é possível, manter contato constante com a turma é importante. Atividades assíncronas e colaborativas podem cumprir, mesmo que de forma limitada, o papel de manter os alunos engajados nas atividades. Tais considerações são feitas tendo em vista o contexto apontado por Paula et al. (2021), no qual os alunos, por mais que tenham dificuldades de acesso em alguns momentos, têm compromisso com a escola e com as atividades didáticas. Segundo os autores, a turma analisada já era engajada anteriormente ao período remoto emergencial. Como já salientado na introdução, outros fatores, externos à escola influenciam no engajamento dos alunos.

A partir das discussões do presente artigo, é salutar indicar que investigações similares à realizada por Paula et al. (2021) considerem diferentes indicadores e instrumentos para a coleta de dados acerca do engajamento dos estudantes, principalmente tendo em vista o caráter multidimensional do construto. Ademais, é necessária a condução de pesquisas em contexto brasileiro que, além de informar a presença ou não de engajamento durante o ensino remoto, explicitem os fatores que o afetam, relacionando-os com as propostas metodológicas e o contexto específico.

Neste diálogo com Paula e colaboradores, espera-se contribuir com o campo ainda escasso de pesquisas sobre os impactos da pandemia da COVID-19 na educação. Afinal, nada garante que outras crises sanitárias como essa não aconteçam no futuro. As pesquisas desenvolvidas sobre esse período lançarão luz às decisões que podem vir a ser necessárias para a educação brasileira.

\section{REFERÊNCIAS}

Affouneh, S., Salha, S., \& Khlaif, Z. N. (2020). Designing quality e-learning environments for emergency remote teaching in coronavirus crisis. Interdisciplinary Journal of Virtual Learning in Medical Sciences, 11(2), 135-137. http://doi.org/10.30476/IJVLMS.2020.86120.1033

Appleton, J. J., Christenson, S. L., \& Furlong, M. J. (2008). Student engagement with school: Critical conceptual and methodological issues of the construct. Psychology in the Schools, 45, 369-386. http://doi.org/10.1002/pits.20303

Araujo, I. S., \& Mazur, E. (2013). Instrução pelos colegas e ensino sob medida: uma proposta para o engajamento dos alunos no processo de ensino-aprendizagem de Física. Caderno Brasileiro de Ensino de Física, 30(2), 362-384. http://doi.org/10.5007/2175$7941.2013 \mathrm{v} 30 \mathrm{n} 2 \mathrm{p} 362$

Bandura, A. (1997). Self-efficacy: the exercise of control. New York: W. H. Freeman.

Baños, J. H., Noah, J. P., \& Harada, C. N. (2019). Predictors of Student Engagement in Learning Communities. Journal of Medical Education and Curricular Development. https://doi.org/10.1177/2382120519840330

Bedenlier, S., Bond, M., Buntins, K., Zawacki-Richter, O., \& Kerres, M. (2020). Facilitating student engagement through educational technology in higher education: A systematic review in the field of arts and humanities. Australasian Journal of Educational Technology, 36(4), 126-150. https://doi.org/10.14742/ajet.5477 
Bergdahl, N., Nouri, J., Fors, U., \& Knutsson, O. (2020). Engagement, disengagement and performance when learning with technologies in upper secondary school. Computers \& Education, 149, 103783. https://doi.org/10.1016/j.compedu.2019.103783

Bergmann, J., \& Sams, A. (2012). Flip your classroom: Reach every student in every class every day. Washington: International Society for Technology in Education.

Blumenfeld, P. C., Soloway, E., Marx, R. W., Krajcik, J. S., Guzdial, M., \& Palincsar, A. (1991). Motivating Project-Based Learning: Sustaining the Doing, Supporting the Learning. Educational Psychologist, 26(3-4), 369-398. https://doi.org/10.1080/00461520.1991.9653139

Bond, M. (2020). Facilitating student engagement through the flipped classroom approach in K-12: A systematic review. Computers \& Education, 103819. https://doi.org/10.1016/j.compedu.2020.103819

Castro, C. J. de, Junqueira, S. M. da S., \& Cicuto, C. A. T. (2020). Ansiedade, Depressão e Estresse em tempos de pandemia: um estudo com alunos da terceira série do Ensino Médio. Research, Society and Development, 9(10), e8649109349. http://dx.doi.org/10.33448/rsdv9i10.9349

Cunha, L. F. F. da, Silva, A. de S., \& Silva, A. P. da. (2020). O ensino remoto no Brasil em tempos de pandemia: diálogos acerca da qualidade e do direito e acesso à educação. Revista Com Censo \#22, 7(3), 27-37.

CETIC (2019). Pesquisa sobre o Uso das Tecnologias de Informação e Comunicação nos domicílios brasileiros - TIC Domicílios. Disponível em: http://data.cetic.br/cetic/explore

Chen, B., Bastedo, K., \& Howard, W. (2018). Exploring Design Elements for Online STEM Courses: Active Learning. Engagement \& Assessment Design. Online Learning, 22(2), 5975. http://doi.org/10.24059/olj.v22i2.1369

Chiu, T. K. F. (2021). Applying the self-determination theory (SDT) to explain student engagement in online learning during the COVID-19 pandemic. Journal of Research on Technology in Education, O(0), 1-17. https://doi.org/10.1080/15391523.2021.1891998

Czerkawski, B. \& Lyman, B. (2016). An Instructional Design Framework for Fostering Student Engagement in Online Learning Environments. Tech Trends, 60, 532-539 (2016). https://doi.org/10.1007/s11528-016-0110-z

Deci, E. L., \& Ryan, R. M. (1985). Intrinsic motivation and self-determination in human behavior. New York, NY: Plenum Press.

Deci, E. L., \& Ryan, R. M. (2008). Facilitating optimal motivation and psychological wellbeing across life's domains. Canadian Psychology, 49, 14-23. https://doi.org/10.1037/07085591.49 .1 .14

Engle, R. A., \& Conant, F. R. (2002). Guiding principles for fostering productive disciplinary engagement: Explaining an emergent argument in a community of learners classroom. Cognition and Instruction, 20(4), 399-483. https://doi.org/10.1207/S1532690XCI2004_1

Espinosa, T., Araujo, I. S., \& Veit, E. A. (2016). Aprendizagem baseada em equipes (TeamBased Learning): um método ativo para o Ensino de Física. Caderno Brasileiro de Ensino de Física, 33(3), 962-986. https://doi.org/10.5007/2175-7941.2016v33n3p962 
Espinosa, T., Araujo, I., \& Veit, E. (2019). Crenças de autoeficácia em aprender Física e trabalhar colaborativamente: um estudo de caso com o método Team-Based Learning em uma disciplina de Física Básica. Revista Brasileira de Ensino de Ciência e Tecnologia, 12(1), 6994. http://10.3895/rbect.v12n1.6020

Faria, A. F. (2008). Engajamento de Estudantes em Atividade de Investigação. (Dissertação de Mestrado). Universidade Federal de Minas Gerais, Belo Horizonte.

Fraysier, K., Reschly, A., \& Appleton, J. (2020). Predicting Postsecondary Enrollment With Secondary Student Engagement Data. Journal of Psychoeducational Assessment, 38(7), 882899. https://doi.org/10.1177/0734282920903168

Fredricks, J. A., Blumenfeld, P. C., \& Paris, A. H. (2004). School Engagement Potential of The Concept. Review of Educational Research, 74(1), 59-109. https://doi.org/10.3102/00346543074001059

Fredricks, J. A., \& McColskey, W. (2012). The Measurement of Student Engagement: A Comparative Analysis of Various Methods and Student Self-report Instruments. In S. L. Christenson et al. (Org.). Handbook of Research on Student Engagement (pp. 763-782). New York: Springer.

Fredricks, J. A., Wang, M. Te, Schall Linn, J., Hofkens, T. L., Sung, H., Parr, A., \& Allerton, J. (2016). Using qualitative methods to develop a survey measure of math and science engagement. Learning and Instruction, 43, 5-15. https://doi.org/10.1016/j.learninstruc.2016.01.009

Freitas, M. de, Heidemann, L. A., \& Araujo, I. S. (2021). Educação nas sociedades do conhecimento: o uso de recursos educacionais abertos para o desenvolvimento de capacidades de ação emancipatórias. EDUR - Educação Em Revista, 37, e20857. http://dx.doi.org/10.1590/0102-469820857

Heller, P., \& Hollabaugh, M. (1992). Teaching problem solving through cooperative grouping. Part 2: Designing problems and structuring groups. American Journal of Physics, 60(7), 637-644. https://doi.org/10.1119/1.17118

Hill, L. G. e Betz, D. L. (2005). Revisiting the Retrospective Pretest. American Journal of Evaluation, 26(4), 501-517. https://doi.org/10.1177/1098214005281356

Irala, V. B., \& Oliveira, G. de L. (2020). As múltiplas abordagens sobre engajamento de estudantes: um estudo descritivo a partir da Plataforma Scielo. In R. M. Rigo, J. A. M. Moreira \& S. Dias-Trindade (Org.). Engagement acadêmico no ensino superior: proposições e perspectivas em tempos de Covid-19 (pp. 105-138). Porto Alegre, RS: Editora da UFSCSPA.

Julio, J., Vaz, A., \& Fagundes, A. (2011). Atenção: Alunos engajados - Análise de um grupo de aprendizagem em atividade de investigação. Ciência \& Educação (Bauru), 17(1), 63-81. https://doi.org/10.1590/S1516-73132011000100005

Keržič, D., Tomaževič, N., Aristovnik, A., \& Umek, L. (2019). Exploring critical factors of the perceived usefulness of blended learning for higher education students. PloS one, 14(11). https://doi.org/10.1371/journal.pone.0223767 
Khlaif, Z. N., Salha, S., \& Kouraichi, B. (2021). Emergency remote learning during COVID19 crisis: Students' engagement. Education and Information Technologies, (0123456789). https://doi.org/10.1007/s10639-021-10566-4

Lee, E., \& Hannafin, M. J. (2016). A design framework for enhancing engagement in studentcentered learning: Own it, learn it, and share it. Educational technology research and development, 64(4), 707-734. http://10.1007/s11423-015-9422-5

Lietaert, S., Roorda, D., Laevers, F., Verschueren, K., \& De Fraine, B. (2015). The gender gap in student engage- ment: The role of teachers' autonomy support, structure, and involvement. British Journal of Educational Psychology, 85(4), 498-518. https://doi.org/10.1111/bjep.12095

Liu, J., \& Zhang, P. (2020). How to Initiate a Discussion Thread?: Exploring Factors Influencing Engagement Level of Online Deliberation. In A. Sundqvist, G. Berget, J. Nolin \& Skjerdingstad K. (Org.). Sustainable Digital Communities. iConference 2020. Lecture Notes in Computer Science, vol. 12051. Springer, Cham.

Marks, H. M. (2000). Student engagement in instructional activity: Patterns in the elementary, middle, and high school years. American Educational Research Journal, 37, 153-184. https://doi.org/10.3102/00028312037001153

Michaelsen, L. K., Knight, A. B., \& Fink, L. D. (2004). Team-Based Learning: A transformative use of small groups in college teaching. Sterling: Stylus.

Moraes, K., Heidemann, L., \& Espinosa, T. (2020). Métodos ativos de ensino podem ser entendidos como recursos para o combate à evasão em cursos de Ciências Exatas? Uma análise pautada nas ideias de Vincent Tinto. Caderno Brasileiro de Ensino de Física, 37(2), 369-405. https://doi.org/10.5007/2175-7941.2020v37n2p369

Nortvig, A. M., Petersen, A. K., \& Balle, S. H. (2018). A Literature Review of the Factors Influencing E-Learning and Blended Learning in Relation to Learning Outcome, Student Satisfaction and Engagement. Electronic Journal of e-Learning, 16(1), 46-55.

Novak, G. M., Patterson, E. T., Gavrin, A., \& Christian, W. (1999). Just-In-Time Teaching: Blending active learning and web technology. Saddle River: Prentice Hall.

Palsolé, S., \& Await, C. (2008). Team-Based Learning in Asynchronous Online Settings. In L. Michaelsen, M. Sweet \& D. X. Parmelee (Orgs.). Team-Based Learning. New Directions for Teaching and Learning (pp. 236-257).

Pasqualetto, T. (2018). O Ensino de Física via Aprendizagem Baseada em Projetos: um estudo à Luz da Teoria Antropológica do Didático. (Tese de Doutorado). Universidade Federal do Rio Grande do Sul, Porto Alegre.

Preast, V. A. (2012). The Development of Team Trust over Time and Its Effect on Performance When Using Michaelsen's Team-Based Learning. (Tese de Doutorado). Iowa State University, Ames.

Paula, H. F., Talim, S. L., Salema, C. S., \& Lamilo, V. R. (2021). Engajamento de estudantes em um Ensino Remoto e Emergencial de Física. Ensaio Pesquisa em Educação em Ciências, 23. 
Reeve, J., \& Tseng, C. M. (2011). Agency as a fourth aspect of students' engagement during learning activities. Contemporary Educational Psychology, 36(4), 257-267. https://doi.org/10.1016/j.cedpsych.2011.05.002

Reeve, J. (2013). How students create motivationally supportive learning environments for themselves: The concept of agentic engagement. Journal of Educational Psychology, 105(3), 579-595. https://doi.org/10.1037/a0032690

Rigo, R. M. (2020). Engagement Acadêmico: contributos das tecnologias digitais para um processo [trans]formativo nas relações de engajamento na Educação Superior. (Tese de Doutorado). Pontifícia Universidade Católica do Rio Grande do Sul, Porto Alegre).

Sasseron, L. H., \& De Souza, T. N. (2019). Students' engagement in Physics lesson: Proposal and discussion of an analysis tool. Investigações Em Ensino de Ciências, 24(1), 139-153. https://doi.org/10.22600/1518-8795.ienci2019v24n1p139

Singh, S., Roy, D., Sinha, K., Parveen, C., Sharma, G., \& Joshi, G. (2020). Impact of COVID19 and lockdown on mental health of children and adolescents: A narrative review with $\begin{array}{llll}\text { recommendations. } & \text { Psychiatry } & \text { Research, } & 293,\end{array}$ https://doi.org/10.1016/j.psychres.2020.113429

Skinner, E. A., Furrer, C. J., Marchand, G., \& Kindermann, T. A. (2008). Engagement and disaffection in the class- room: Part of a larger motivational dynamic? Journal of Educational Psychology, 100(4), 765-781. https://doi.org/10.1037/a0012840

UNESCO (2020). COVID-19 Education Response. Disponível em: https://en.unesco.org/covid19/educationresponse/globalcoalition

Vansteenkiste, M., Zhou, M., Lens, W., \& Soenens, B. (2005). Experiences of autonomy and control among Chinese learners: Vitalizing or immobilizing? Journal of Educational Psychology, 97(3), 468-483. https://doi.org/10.1037/0022-0663.97.3.468

Veiga, F. H., Reeve, J., Wentzel, K., \& Robu, V. (2014). Assessing students' engagement: A review of instruments with psychometric Qualities. In Envolvimento dos Alunos na Escola: Perspetivas Internacionais da Psicologia e Educação / Students' Engagement in School: International Perspectives of Psychology and Education (pp. 38-57). Disponível em: http://repositorio.ul.pt/handle/10451/18036

Vieira, K. M., Postiglioni, G. F., Donaduzzi, G., Porto, C. dos S., \& Klein, L. L. (2020). Vida de Estudante Durante a Pandemia: Isolamento Social, Ensino Remoto e Satisfação com a Vida. EaD Em Foco, 10(3). https://doi.org/10.18264/eadf.v10i3.1147

Vollet, J. W., Kindermann, T. A., \& Skinner, E. A. (2017). In peer matters, teachers matter: Peer group influences on students' engagement depend on teacher involvement. Journal of Educational Psychology, 109(5), 635-652. https://doi.org/10.1037/edu0000172

Wentzel, K. R. (1997). Student motivation in middle school: The role of perceived pedagogical caring. Journal of Educational Psychology, 89(3), 411-419. https://doi.org/10.1037//0022-0663.89.3.411 


\section{Tobias Espinosa}

Licenciado em Física, Mestre e Doutor em Ensino de Física

Professor do Instituto de Matemática, Estatística e Física da Universidade Federal do Rio Grande, Campus Santo Antônio da Patrulha, RS, Brasil.

E-mail: tobiasespinosa@furg.br

Contato:

Universidade Federal do Rio Grande, Campus Santo Antônio da Patrulha Rua Barão do Cahy, 125, Cidade Alta - Santo Antônio da Patrulha, RS - Brasil

CEP 95500-000

Editor Responsável:

Glauco dos Santos Ferreira da Silva

Contato

Centro de Ensino de Ciências e Matemática de Minas Gerais - CECIMIG

Faculdade de Educação - Universidade Federal de Minas Gerais revistaepec@gmail.com 